more humane society. Remember that nations' attitudes are just the same as the attitudes of its individual members. I am sure that most of us present here have a positive attitude. So, let us make known our efforts and our science, to improve humanity. I feel strongly impelled to do so.

\title{
Educational Material in Developing Countries
}

The panel discussion on textbooks stimulated a great deal of interest and discussion, especially about the problem of educational material in and for the developing countries. About 50 participants in the Colloquium therefore reconvened one afternoon for an impromptu open discussion of this problem. the following notes were compiled by John R. Percy; they are based on the comments and suggestions of many participants.

\section{Acquiring Current Material from Abroad}

Current monographs and journals are essential for graduate teaching and research, and for the "professional development" of instructors, but there are major problems resulting from currency shortages or restrictions. Institutions must therefore be particularly selective in choosing material. IAU Commission 46 produces a triennial listing of astronomy education material in all major languages to help to deal with this problem. Institutions in developing countries can obtain some periodicals through exchange which institutions elsewhere, but problems of language, content, and shipping costs make this difficult. Another approach might be to "twin" institutions in the developing and the developed countries.

\section{Acquiring Less-Current Material from Abroad}

Several organizations are now engaged in collecting unused books and journals, and sending them to developing countries ${ }^{3}$. Publishers might be also induced to donate material, such as slightly-outdated editions of textbooks. In North America, new editions of introductory astronomy textbooks are introduced approximately every three years!

\section{Producing Translations of Important Material}

Translations of important and popular material could be made in the language of the developing country (and then shared by other countries with the same language). This makes good use of good material, but requires the cooperation of the author and publisher of the original edition. It also requires a good translator, who is willing to do it as a "labor of love": there is not much profit to be made in translating the average astronomy book! In the case of elementary and secondary school

\footnotetext{
${ }^{3}$ See the article by Batten and Brückner elsewhere in these proceedings.
} 
textbooks, there may be a larger market, but there are also additional problems. The book may have to be translated into several local languages (the example of India was quoted). Most school textbooks are written for a specific curriculum, which is far from standard from country to country.

\section{Reprinting Material Locally}

With the cooperation of the author and publisher of the original edition, certain books and journals could be reprinted locally, to take advantage of lower labor and shipping costs. These low-cost editions could then be used in other developing countries. Some projects of this kind have been undertaken by organizations such as UNESCO.

\section{Reprinting Material Locally, with Modifications}

One problem with acquiring or reprinting "foreign" material is that such material may not reflect the cultural and scientific environment of the developing country. This is particularly true for popularizations and for school textbooks. With present developments in electronic or "desktop" publishing, however, it may be possible for an author or publisher to provide the text and illustrations for a book in electronic form. These could then be modified to fit the local environment, and printed locally in order to take advantage of lower labor and shipping costs.

\section{Local Authorship and Publication}

As a developing country evolves into a developed country, the ultimate goal might be to produce all educational material locally. During the transitional phase, this is probably feasible only for standard textbooks. The few potential authors of such books are usually overloaded with the task of developing the local astronomy education system, and local publishers are reluctant to produce books for a limited market.

\section{Discussion}

C. Harper: Modern astronomy is derived from the astronomy that developed in western Europe. It will be a great loss if the alternate astronomies that arose elsewhere round the globe disappear.

The developing and the developed countries could do much more to recover and preserve the original native astronomies that emerged in their own regions. For instance, teachers of astronomy in New Zealand have opportunities to draw upon the rich heritage of the astronomical knowledge of the Maori. The cultural needs of individual countries can be served by incorporating regional native astronomies in introductory astronomy courses. 